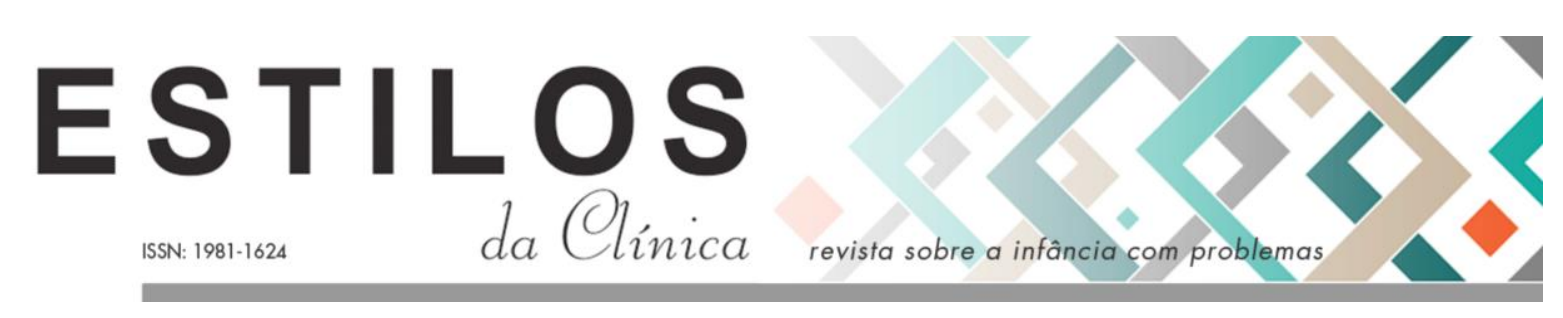

DOI: https://doi.org/10.11606/issn.1981-1624.v00i0 p371-377.

\title{
Resenha
}

Por que Ferenczi?

Kupermann, D.

São Paulo, SP: Zagodoni Editora, 2019, 175p.

\section{Por que Ferenczi hoje?}

\section{Bartholomeu Vieira}

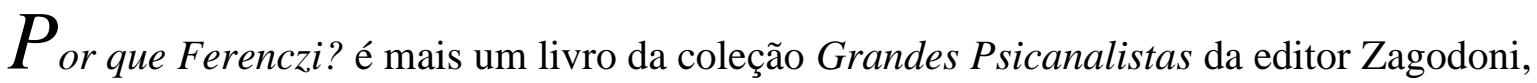
cujo leitmotiv é tanto apresentar ao público interessado nos grandes nomes da psicanálise o pensamento de cada um dos autores relevantes à constituição desse campo como reafirmar a potência original de cada um deles, ao seu modo próprio, em filiação a Freud. Na obra em questão, Daniel Kupermann adota uma estética monográfica enfatizando os diversos impasses clínicos desdobrados pela clínica psicanalítica nos primeiros trinta anos de sua constituição. Porém, mais do que o recurso à história da psicanálise por sua clínica, o fio condutor desse livro demonstra como Ferenczi apura a teoria da técnica criando uma ética norteada pela via sensível da clínica ao articular de forma original a noção de perlaboração (Dürcharbeitung) exposta por Freud.

De linguagem precisa, mas também delicada, a forma como Kupermann convida seu leitor a conhecer a obra de Sándor Ferenczi demonstra tanto o conhecimento que o autor tem a respeito do psicanalista húngaro como sua capacidade de misturar inúmeros elementos heterogêneos sem cair em dialéticas e binarismos simples, mantendo, assim, a todo tempo, a tensão inerente ao tema de que escolheu tratar e a profunda fidelidade ao método utraquista de Ferenczi. O estilo de escrita praticado por Kupermann estimula o leitor a se envolver com os conteúdos do livro de um jeito tipicamente ferencziano, ou seja, emocionalmente guiado por uma linguagem sustentada pelo paradoxo, capaz de provocar e despertar a criança freudiana que habita em cada um - criança vitalizada e pulsante, que denuncia as hipocrisias com suas perguntas inconvenientes e reveladoras.

1. Psicanalista, Mestre em Psicologia Clínica pela Universidade de São Paulo, São Paulo, SP, Brasil. E-mail: bartholomeu.vieira@gmail.com 
Dessa escrita vigorosa, o que há de mais original em nossa disciplina fica em evidência justamente por corajosamente ir contra, com boa dose de teimosia do autor, as transferências cruzadas que subjazem a algumas propostas de Formação Psicanalítica demasiadamente civilizatórias e responsáveis por um padrão de analistas meramente normais.

Desde o começo do livro, o leitor poderá ver quão incisivas são as propostas ferenczianas, já que diretamente questionadoras do fazer do psicanalista. Disso podemos ter certeza absoluta. Ferenczi jamais recuou frente ao desafio clínico com os chamados casos difíceis, tampouco de reformulações teóricas da psicanálise; fosse enfatizando os impasses ou narrando conceitos, temos nesse psicanalista uma inspiração, graças ao seu estilo criativo, jovial e reconhecidamente sensível na lida com as problemáticas clínicas das mais complexas.

Há alguns anos que o renascimento do pensamento de Ferenczi vem ocupando o cenário psicanalítico. A suspensão da mortalha de silêncio imposta sobre o seu pensamento não se limita à mais do que merecida justiça histórica: trata-se de reabilitar grande parte da potência do dispositivo clínico graças às suas brilhantes reflexões e modificações técnicas. Esse renascimento é um verdadeiro ato de "soltar as línguas" (Ferenczi, 1933/2010) dos próprios psicanalistas, que, uma vez livres do fantasma dos imperativos superegoicos de performance transmitidos por formações hipócritas, podem voltar a praticar gestos de cuidado, guiados por uma ética hospitaleira, empática e de sólida formação experiencial com o inconsciente.

O começo do livro aborda a problemática referente ao trabalho com os pacientes excessivamente bem adaptados e submissos às imposições do método clássico - pacientes esses que, paradoxalmente, obedeciam à regra das associações, mas se rebelavam contra o trabalho do inconsciente. Esse é o caso de Serguéi Pankejeff, paciente considerado por Freud de grande inteligência, que, por sua vez, era desconectado da vida pulsional e se aliava a uma anestesia da afetividade, mantendo a análise estagnada após três anos de tratamento. Diante desse impasse, Freud postula uma medida ativa de anunciar o encerramento do caso em poucos meses. A complexidade dos efeitos dessa medida são avaliadas tanto pelo próprio analista do caso como por Ferenczi e são ponderações a respeito dos limites da técnica e mesmo de seu potencial iatrogênico. Abre-se então caminho para uma necessária modificação do modo de psicanalisar.

Em nome do princípio de abstinência e por meio da promoção da frustração e da emergência de afetos hostis, a atividade do analisando é a forma como Ferenczi pondera a modificação técnica necessária, avaliada no segundo capítulo do livro. Nesse momento, Kupermann constrói uma argumentação em torno do problema de como tirar os pacientes da indiferença e sobre que tipo de pacientes seriam esses. A técnica ativa proposta por Ferenczi se mostra uma alternativa contra o estancamento de análises em que pacientes obedientemente se defendem do mal-estar necessário à análise através de uma compulsão de associações, da indiferença emocional ou mesmo de derivações muito criativas da libido para o corpo.

A técnica ativa tanto se propunha como um direcionador para as análises que já estavam em momentos avançados, mas que se estagnavam como um recurso para criar analisabilidade em pacientes que frequentavam os consultórios, mas que não entravam, de fato, em um processo de análise. Como sintetiza Kupermann, o melhor da técnica ativa tem por objetivo tanto a destruição de trincheiras da resistência como "o alargamento da efetividade das práticas de cuidado que caracterizam a psicanálise desde o seu surgimento" (p. 46). Provocar fantasias é estimular os pacientes - com injunções e proibições - a darem vazão verbal a conteúdos apaixonados, eróticos ou hostis que não conseguem chegar à consciência pela 
associação livre, mas que podem ser revividos em forma de repetição na relação com o analista.

Imprudência, destemor ou grande intimidade com o cerne da técnica: essas são algumas possibilidades de pensar a ousada proposta ferencziana do período da atividade e sua sequência. São apenas algumas entre tantas outras, cabendo ao leitor a difícil tarefa de perlaborar, ao seu modo e no seu tempo, as próprias conclusões quanto à importância desse recurso que não foi de todo abandonado, como Kupermann faz questão de evidenciar através do exemplo que Julia Kristeva conduziu em seu livro Novas doenças da alma, no qual o caso Didier demonstra que a necessária ruptura do silêncio do analista leva a análise por caminhos diferentes, com o empréstimo de fantasias e com o exame de um material intersubjetivo.

Mesmo ficando claro que a atividade faz parte do mundo do analisante, restando ao analista a ativação de sua afetividade para que este contribua com a perlaboração das intensidades traumáticas, ficou claro que o método de tentar acelerar processos de análise está fadado ao fracasso quando Kupermann nos conta sobre o retorno de Pankejeff ao divã.

Entendendo que o Homem dos Lobos acabou acometido de um agravamento de sua condição, chamada por Kupermann de "maldição egípcia", surge uma indicação importante em nome da paciência que os analistas devem ter diante das repetições que caracterizam a transferência. Favorecer repetições através do agieren, legítimas herdeiras da catarse dos tempos de Breuer, tornou possível avançar análises paradas e tornar analisáveis pacientes antes inacessíveis. Isso feito via intervenção ativa, mais contribuiu para comprometer a relação analítica e impossibilitar seu aspecto relacional contaminando a transferência positiva. Em suas contraindicações, o próprio Ferenczi reconheceu como o recurso à atividade do paciente muitas vezes serve de desculpa para sadomasoquismo ou posturas professorais por parte dos analistas. É assim que, na sequência de sua argumentação, no capítulo três do livro, Kupermann investiga a especificidade dos adoecimentos anímicos dos pacientes limítrofes reafirmando o compromisso da psicanalítica com seu elemento preponderante: a Clínica.

A hipótese do hóspede não bem-vindo e da prevalência da pulsão de morte no começo da vida ganham forma no pensamento ferencziano. Os pacientes marcados pelo trauma se comportam como um pequeno pardal, subjugado pela força superior de um falcão predador; entram em desespero (helplessness) e assumem a sua própria destruição como única forma de manter a vontade individual, movidos apenas pelo desespero. Assim, a autodestruição se constitui como a base da forma de existir desses pacientes, que vivem momentos de marcado estado sonambúlico e devaneio, presos na compulsão à repetição de obter a gratificação de serem desejados da mesma forma terrível como a que ocorreu em sua vida infantil primitiva (cf. Severn, 1933/2017).

Essa situação narra a particularidade do desmentido, termo que Kupermann faz questão de estender à pormenorizada elucidação metapsicológica e explanatória. Situação essa de transformação de seu amor terno em uma dependência tirânica, o desmentido marca um tipo de violação psicossomática que ocorre em três tempos e que costuma ser praticada segundo as modalidades das punições carregadas de paixão ou da responsabilização da criança pelo sofrimento do adulto. Segundo Kupermann, a especificidade do desmentido (Verleugnung) que Ferenczi aponta está justamente em seu aspecto relacional: "é o ato realizado pelo adulto sobre a criança que a ele recorre em busca de auxílio para significar a violação que lhe foi imposta pelo agressor. Um mecanismo intersubjetivo" (p. 62). A escolha de Kupermann pelo termo "desmentido" é um esforço em demonstrar a força da ambiguidade entre verdadeiro e falso, de negação de evidências, de percepções, e a tentativa de sustentar uma mentira de 
forma relacional, entre um par adoecido - o abusador e o abusado. Assim, o desmentido atua sobre todos os participantes da cena traumática: do adulto louco e confuso, cuja culpa inconsciente obnubila o raciocínio, e da criança acometida por dúvida diante de seus sentimentos e sensações corporais, que acaba se identificando com a agressão e o agressor, incorporando a culpa inconsciente do outro e vivendo-a como agonia, vergonha relacional e impulsividade hetero ou autoagressiva.

O indizível do trauma, ato deflagrador da condição existencial dos pacientes de Ferenczi, ocorre em três movimentos e começa pela violação da confiança de uma criança por um adulto amado, situação que busca testemunho, mas que, infelizmente, encontra o silenciamento quando um outro adulto de confiança não é capaz de produzir escuta sensível. Configura-se um tempo do desmentido com "o abandono daquele que fora requisitado para autenticar e significar a violação por meio do reconhecimento da dor que se apoderou do ser da criança" (p. 59). A tragédia psíquica narrada tem efeitos avassaladores sobre a constituição da personalidade, e o psicanalista deverá intervir, precisamente, no resgate da confiança perdida.

Enfatizando a especificidade e a relevância das repetições sob transferência, Kupermann avança sua tese a respeito da trajetória de Ferenczi enquanto autor da psicanálise responsável por compreender o papel da perlaboração na clínica. As propostas ferenczianas embrionárias a respeito da construção da confiança, da escuta empática e da sensibilidade do analista atingem seu apogeu teórico a partir de 1928, no período que Kupermann define como "momento de virada teórica", parte nuclear do livro Por que Ferenczi?

Um momento de virada teórica é visto como um tipo de retorno que não pretende alcançar uma verdade última ou arriscar fechar um sentido unívoco na instauração de uma discursividade, e sim promover uma nova abertura - por meio do reconhecimento das diferenças. Um exemplo de virada praticado por Ferenczi está na noção de adaptação. Diferente da proposta freudiana, que assume sua submissão ao princípio de realidade, Ferenczi postula um aspecto relacional para a adaptação: é o mundo que precisa se adaptar às necessidades da criança nos momentos primitivos. As consequências clínicas para uma modificação desse porte inauguram uma clínica ambientalista, relacional e voltada à Potência. Resumidamente, como o autor do livro aponta, "o analista é que precisaria dispor da maleabilidade elástica necessária para atender aqueles que até então eram considerados inanalisáveis" (p. 91). E, neste momento, podemos retornar ao começo do livro, com a apresentação do caso do Homem dos Lobos: tentar modificar a técnica de modo que pudéssemos intervir no paciente para que ele, por sua vez, melhor se adaptasse ao modo de fazer clínico da associação livre e da interpretação, na verdade, demonstrou que o sucesso da intervenção apenas favoreceu a submissão do paciente à influência hipnótica do analista, que, apesar de contida em qualquer tratamento, nessa situação, auxiliou na progressão do trauma, tornando o paciente um subproduto da história da psicanálise - um destino tão funesto.

Mas, afinal, o que era necessário modificar? Kupermann sintetiza a obra ferencziana enquanto um estilo empático, marcado pela disponibilidade afetiva ao encontro, a possibilidade de mistura e o seu devido afastamento para diferenciá-la da forma clássica da interpretação que foi ensinada por Freud - deixando claro que não se trata de uma ruptura, mas sim da contraposição de uma modalidade de ação diante de um cenário clínico específico. Inscrevendo Ferenczi como o inaugurador e promotor de uma corrente da psicanálise, Kupermann comenta que, "assim como não existe um bebê sem cuidador, também não há desamparo sem uma perspectiva relacional que envolva a presença do outro" 
(p. 94). É nessa dimensão que não há um trauma do nascimento. O desamparo ocorre quando a intervenção dos adultos no cuidado com a criança não é eficiente. $O$ sujeito que não pode passar com tranquilidade, isso é, adaptação do ambiente pelas fases naturais de onipotência, se vê desamparado diante da dureza da vida, pois não consegue acessar os próprios recursos criativos.

Ferenczi não nos fala de uma clínica da neurose clássica. $\mathrm{O}$ autor traz para o centro da problemática dos casos graves o núcleo traumático, relativo à questão relacional da constituição do psiquismo. Diante da clínica contemporânea, o pensamento de Sándor Ferenczi se torna um auxílio importante. Hoje, torna-se frequente lidar com analisandos marcados por um laço emocional inicial da vida caracterizado por um vínculo intenso, ambíguo e confuso, uma série de duplos vínculos com figuras de cuidado que fizeram emergir sofrimentos narcísicos; sujeitos que sofreram comprometimentos terríveis porque não puderam desfrutar (por motivos que não sabemos) do momento em que deveriam ter sido objeto de amor nas fases mais iniciais da vida. Sem a experiência de onipotência natural da primeiríssima infância, estão marcados pela dificuldade de fazer lutos, vivendo a clivagem, a identificação melancólica e as fantasias onipotentes, esses analisandos paradoxais demonstram sensibilidade e percepção de si e dos outros aguçada - por mais que clivada -, intelecto operacional elevado e modos de vida pujantes - porém marcados pela destruição que, sem uma intervenção analítica, dificilmente se tornam formas de devir.

Se a experiência com a técnica ativa mostrou que o setting psicanalítico não está protegido de se tornar uma prática sádico-masoquista, na qual um tipo de adaptação mimética estacionária, decorrente do medo do abandono, pode produzir a identificação traumática, a dita experimentação mostrou como a direção do tratamento não é fazer, por efeitos mágicos de sugestão autoritária, o paciente relembrar algum material. Como o caso de Serguei ensinou de forma custosa, o necessário é perlaborar aquilo que se atualiza na transferência. Assim, se exige do analista uma nova atitude: ele deve realizar um verdadeiro trabalho psíquico em conjunto com o analisando que consiste em uma ação de construção ou reconstrução de materiais por parte do analista, que deve saber "como, quando e com que explicações" comunicar ao seu analisando determinadas construções feitas em análise.

A neocatarse será a solução ferencziana, herdeira dos impasses técnicos com os casoslimite, possibilidade unicamente exequível, diante da paciência dos analistas, para que tanto a repetição como a transferência negativa possam se manifestar plenamente no decurso da análise. Será pelas vias do que Ferenczi chama de "regressão thalássica" e de jogo compartilhado que a neocatarse trará de volta à Clínica psicanalítica o fator "intensamente emocional, de tipo hipnótico-sugestivo (p. 136)", que era o fator de cura das épocas de Breuer.

O resgate da confiança através da criação de um setting elástico proporciona a emergência do irrepresentável. Estados regredidos de consciência guiados por processo primário, transes e fenômenos de dissociação constituem uma nova estética do encontro e passam a ser parte fundamental do trabalho dos analistas pertencentes à "Escola da autenticidade de Ferenczi" (Lacan, 1955/1998). Na medida em que produz regressão, obnubilação e fenomenologia hipnagógica semelhante aos estados confusionais, a neocatarse mobiliza um modo de trabalho guiado pelo jogo, alcançando a realidade etiológica do adoecimento psíquico e propondo um modo de atravessar os fragmentos a partir das construções em análise. Como bem diz Kupermann, "O irrepresentável, por não poder ser significado em palavras, era apresentado por meio de materializações corpóreas e exibições de fragmentos de repetição atuados pelo 
analisando" (p. 13). Mais ainda, a argumentação estabelecida por Kupermann ao longo do livro demonstra como a neocatarse é tanto o resultado de profunda e incontestável fidelidade às balizas fundamentais propostas por Freud como uma solução para os impasses clínicos, sendo o resultado de uma interlocução íntima entre os autores.

Se refletirmos a respeito da proposta ferencziana para a psicanálise, teremos, em linhas gerais, que seus objetivos clínicos visam a autenticidade através do desmonte da lógica do desmentido; experimentar graus de integração da personalidade possíveis através da continuidade na experiência com os fragmentos e ampliar a Potência humana (cf. Rozenthal, 2014) através da experimentação dos estados de regressão; constituir uma linguagem capaz tanto de narrar o Self a partir da linguagem da ternura - "delicada e sacana, terna e ao mesmo tempo obscena, herdeira da perversão polimorfa que caracteriza os estágios pré-genitais do desenvolvimento da libido" (p. 106), como de perlaborar intensidades afetivas, provenientes da paixão. Essas seriam as direções da cura que Ferenczi incansavelmente buscou.

Para que todos esses objetivos sejam alcançados pelo paciente, o analista deve, ele também, alcançar objetivos - e essa é uma das lições que Ferenczi nos ensina: a relevância da metapsicologia do analista. Ele precisa adquirir a competência de compartilhar uma linguagem capaz de alcançar e afetar a parte apartada da consciência de seu paciente. Ele deve falar com a criança, e não da criança, mantendo uma distância precisa: próxima o bastante para favorecer a sensibilidade proveniente de recursos identificatórios e projetivos, mas sem, com isso, perigar mistura alienante. É assim que a leitura de Kupermann mostra como Ferenczi foi o responsável por criar uma clínica mobilizada pela ética do cuidado, isso é, um estilo empático do analista guiado pela hospitalidade. Dirá o autor:

\begin{abstract}
A principal consequência clínica das formulações de Ferenczi sobre a traumatogênese foi o entendimento de que é o método psicanalítico, e cada psicanalista em particular, que deveria se adaptar ao tempo, ao ritmo e à singularidade do sofrimento de cada analisando, e não o contrário. Dessa maneira, a escuta dos pacientes considerados inanalisáveis indicara seu avesso - os limites da técnica padrão" (p. 150).
\end{abstract}

É com esse conjunto de argumentos que vemos como o percurso do livro de Kupermann conduz uma resposta para a questão de seu título. Afinal, por que Ferenczi? Porque esse autor foi o responsável por acompanhar Freud minuciosamente, desenvolvendo diversos impasses clínicos de forma não apenas criativa como também preocupado com a eficácia dos resultados dos tratamentos. Paladino da psicanálise, discípulo fiel e criança terrível, Sándor Ferenczi é um cofundador da própria Psicanálise que não procurou jamais romper seus laços com a comunidade dos analistas, tampouco se intitular como um suposto verdadeiro representante do movimento. Se Freud criou essa disciplina, Ferenczi aprimorou de forma legítima e autorizada os seus operadores.

Particularmente, acredito que o livro em questão nos remete a um fator da maior pertinência, nem sempre levado suficientemente em consideração, mas que merece nossa pormenorizada atenção. Tenho a impressão de que Freud deixou claro que a transferência age (Agieren) as paixões na relação com o analista, no momento presente da sessão e na extensão de um tratamento e é essa ideia que deve prevalecer em nossa mente com a força que Freud de fato atribuiu a ela quando reconheceu que é necessário ter paciência para que tais paixões sejam trabalhas no tempo (cf. Figueiredo, 2019) específico de uma análise. A esse respeito, Ferenczi respondeu como fazê-lo: através de um método que convoca os analistas para uma neocatarse de tais forças. É nesse sentido que vemos o mais potente de uma psicanálise: ninguém se beneficia de meras interpretações de representação; nossa prática definitivamente 
me parece, cada vez mais, um trabalho de construção, guiado pelo Amor e voltado ao Cuidado através da Sensibilidade Reparatória.

\section{Referências}

Ferenczi, S. (2010). Confusão de língua entre os adultos e a criança. In S. Ferenczi, Psicanálise IV (Obras Completas de Sandor Ferenczi, 4). São Paulo: Martins Fontes. (Trabalho original publicado em 1933).

Figueiredo, L. (2019). Os Tempos em análise (Ideias a partir da psicanálise e da prática psicanalítica). Cadernos de Psicanálise (CPRJ), 41(40), 21-34. Recuperado de http://cprj.com.br/ojs_cprj/index.php/cprj/article/view/135

Kupermann, D (2019). Por que Ferenczi? São Paulo: Zagodoni.

Lacan, J. (1998). Variantes do tratamento-padrão. In J. Lacan, Escritos (V. Ribeiro, trad.). Rio de Janeiro: Jorge Zahar. (Trabalho original publicado em 1955).

Rozenthal, E. (2014). O ser no gerúndio, corpo e sensibilidade na psicanálise. Rio de Janeiro: Companhia de Freud.

Severn, E. (2017). The discovery of the self: A study in psychological cure. Philadelphia: Taylor \& Francis. (Trabalho original publicado em 1933).

Recebido em julho/2019 - Aceito em agosto/ 2019. 